\title{
PERSPECTIVAS DE LA EXISTENCIA EN LA OBRA POÉTICA DE CONCHA LAGOS
}

\author{
THE PERSPECTIVES OF THE EXISTENCE \\ IN CONCHA LAGOS' POETIC WORK
}

\author{
Ana Palomo Ortega \\ Universidad de Córdoba
}

Resumen:Teniendo en cuenta la problemática de la inclusión de las escritoras de los años 50 en la nómina de su tiempo, el presente artículo tiene por objeto poner de relieve la obra poética de Concha Lagos para poder así hacer justicia a una de las propuestas más granadas de la literatura española. Sin lugar a dudas, tanto la producción de Lagos como la de la mayoría de mujeres poetas de esta época han sido a lo largo de la historia de la literatura excluidas del canon por un motivo fundamental: la persistente ideología patriarcal que ha imperado en nuestro país hasta muy recientemente. Por ello, ha de considerarse este estudio como una muestra más de la necesidad de manifestar nuestra realidad literaria desde todos sus ángulos, para lo que se abordará el análisis de las distintas perspectivas de la existencia plasmadas por nuestra autora en su obra.

Palabras clave: poesía; existencia; escritura de mujer; identidad.

Aвstract: While taking into account the problem of the inclusion of the 50s female writers among the list of authors at that time, the present article aims at highlighting Concha Lagos's poetic work in order to receive due recognition, being one of the most important lyric work in the Spanish literature. Without a doubt, Concha Lagos's poetry, as well as other female writers' work in those days, has been excluded from the canon throughout the history of the literature due to a major reason: the persistent patriarchal ideology that has been prevailing in our country until recently. As a consequence, we must consider this study as a proof of the need to expound the literary reality in Spain from each of its angles; therefore, we deal with all the different perspectives of the existence depicted by this poet in her work.

KEY-WORDS: poetry; existence; female writers; identity. 


\title{
PROBLEMÁTICA DE SU FILIACIÓN \\ GENERACIONAL, INFLUENCIAS \\ Y CLAVES POÉTICAS
}

El presente artículo tiene por objeto el tratamiento de la producción poética de Concepción Gutiérrez Torrero, más conocida en el espacio literario como Concha Lagos. Para tratar la obra de esta autora hemos de tener en cuenta, en un primer momento, que no todos los críticos la incluyen entre los escritores de los años 50, puesto que algunos de los asuntos que refleja en su poética permiten englobarla en la poesía del 36. Esta sería una de las causas, según refiere Blas Sánchez Dueñas, que permitiría justificar su exclusión literaria:

Concha Lagos es una autora cuya falta de adscripción explícita a alguna de las corrientes literarias dominantes de su tiempo, así como su tardía llegada a la literatura ha provocado su aislamiento poético a pesar de haber sido una de las principales protagonistas literarias de su tiempo. Este desclasamiento o desubicación hace que algunos críticos la sitúen en la conocida como "Generación del 36", mientras que otros la ubican en los poetas del «Grupo del 50» (Sánchez Dueñas, 2011: 10) ${ }^{1}$.

Lo anterior se pone de manifiesto en antologías como la de José María Balcells, quien la incorpora en el apartado de poetas pertenecientes a la "Primera promoción de posguerra», situándola junto a otras escritoras muy renombradas de esos años:

\begin{abstract}
Además de Carmen Conde, María Cegarra, Elena Martín Vivaldi y Ángela Figuera, en esta primera promoción poética surgida tras la guerra civil han de ser citadas Pino Ojeda, Concha Zardoya, Concha Lagos, Gloria Fuertes y Sagrario Torres (Balcells, 2003: 27).
\end{abstract}

Las denominaciones citadas entre comillas han sido tomadas de García Tejera y Fernández Guerrero $(2003 ; 2005)$, a quienes Sánchez Dueñas cita entre paréntesis y en la bibliografía final de su artículo. Conviene consultar dicha bibliografia, pues contiene referencias de gran relevancia en relación con el tema que nos ocupa. 
No obstante, Balcells apunta que esta inclusión, tanto de Concha Lagos como de Gloria Fuertes y Sagrario Torres, entre las poetas de posguerra, se debe más a un criterio cronológico de nacimiento que a los rasgos poéticos de cada una de ellas, los cuales guardan mayores semejanzas con los del resto de poetas del 50. Considera que es conveniente situarlas en este grupo poético, aunque no da una explicación verdaderamente aclaratoria del porqué de esta decisión.

Concha Lagos desarrolla en su obra poética un amplio abanico temático, pero en este trabajo nos detendremos fundamentalmente en los motivos y asuntos que guardan cierta relación con la problemática existencial, la búsqueda de su propia identidad y su relación con «los otros».

El primero de sus poemarios publicados es Balcón (1954), «un libro interesante no por lo que daba, sino por lo que prometía", según José Hierro (en Miró, 1976: 12). En efecto, como sugiere esta valoración del poeta cántabro, la obra de Lagos supone un crescendo, por lo que aquello que esboza en sus primeras creaciones es llevado al grado de significación más profundo en sus últimos poemarios. Para comprender esta gradación, hemos de atender a las consideraciones de la propia autora acerca de lo que significa para ella la creación poética, además de al reconocimiento explícito de influencias en sus poemarios. En este sentido, resulta de gran utilidad, y testimonio de incalculable valor, la monografía de Alfredo Gómez Gil (1981), puesto que recoge varias entrevistas en las que nuestra autora habla abiertamente sobre los asuntos que nos ocupan. El detenimiento en estas cuestiones, por tanto, nos proporcionará numerosas claves para la comprensión y el sentido último de la obra lagosiana.

En cuanto a la génesis y al motivo de su escritura, la propia autora reconoce que su vocación literaria nace tras su matrimonio: «me casé muy joven, y ha sido después de casada cuando verdaderamente sentí la necesidad de dar a la luz mis emociones artísticas a través de la pluma» (en Gómez Gil, 1981:52). Esta afirmación recoge una declaración existencial profunda. Tanto es así, que Lagos nos presenta ya el quehacer poético no solo como evasión de su vida cotidiana, sino como trasunto de su propio vuelo, de la creación de su identidad, de su desasirse de las tareas domésticas — unidas ineludiblemente al matrimonio- como única salida a la vida que 
había escogido, pero siempre viendo claro que no censuraría su necesidad de realizarse en todas las dimensiones de su vida. El vuelo al que nos referimos aparece en muchos de sus poemas, tratado desde una doble perspectiva. Versos como «Recortarme las alas / hasta quedar suspensa / en la formal postura» (Lagos, 1976: 130), pertenecientes al poema "Tregua», de Tema fundamental (1960), o la composición «Sea», de Luna de enero (1960), en la que la poeta reconoce la imposibilidad de volar, evidencian que la pasividad del sujeto lírico femenino es conmovedora:

AGUA sumisa al pez de tu capricho.

Tú me quieres así, yo digo: «sea» y nos navega el cielo por el fondo.

Tú me quieres de estar casi en ausencia, media luz de tu paz y de tu frente, sujeta a la distancia en que me cercas.

Tú me quieres en gris como la tarde.

En oración, en sueño, de silencios; ala cortada y mano sobre mano.

Tú me quieres de espera y de ternura, al aire de tu tiempo y de tu aire, surco de amor tendido a tu semilla (ibíd.: 99).

Por otro lado, nuestra poeta no se resiste a esa visión existencial de la mujer: en los versos de "Todo será silencio», de La soledad de siempre (1958), el sujeto lírico reconoce sus ansias de alzar el vuelo antes de perecer; esta será la principal postura de la escritora ante su mundo y sus circunstancias. A pesar de la toma de conciencia por parte del yo poético de su realidad existencial, el anhelo de sublimidad que aparece en estos versos nos muestra la actitud vital de Lagos:

Me crezco cual la llama en estas rebeldías antes de que las alas se resistan al vuelo.

Después ya lo sabemos, será silencio todo.

Silencio y más silencio.Tan solo un gran silencio (ibíd.: 76).

Por su parte, numerosas composiciones de importantes poemarios de temática existencial, como son Los obstáculos (1955), Tema fundamental y Golpeando el silencio (1961), remiten a la palabra 
creadora como tabla de salvación y clave de vitalismo existencial. Sin embargo, la creación es arriesgada, teniendo en cuenta que, como reconoce María Rosal,

[n]o podemos olvidar, cuando analizamos la poesía escrita por mujeres, que el sujeto de la enunciación se inscribe en un orden simbólico que reproduce el falogocentrismo de la cultura occidental, por lo que la práctica discursiva muestra las relaciones de poder que sustentan el discurso (Rosal, 2010: 240).

Sin lugar a dudas, algunos de los poemas de Lagos se encuentran inscritos dentro de este orden simbólico. Atendamos a esta muestra de Los obstáculos:

YO quisiera fundirme en el río de la vida
y arqueando los brazos crear puentes,
unir orillas;
sentir vuestras pisadas en desfile compacto.

No sonriáis: ya sé que soy mujer.

Solo podré tenderos puentes de esperanza, de sonrisas, de amor; puentes donde acunaros (Lagos, 1976: 41).

En estos versos se aprecia el desdoblamiento del sujeto lírico, quien apela a su otro "yo». El despertar de la otredad remite, además, a la latente reivindicación de la identidad femenina que aparece en esta y otras composiciones. El poema se presenta claramente dividido en dos estrofas de cuatro versos: la primera de ellas, que podríamos calificar como «la más alta», muestra el ansia del yo poético de alzar el vuelo, metáfora del anhelo de libertad de Lagos, que recoge su reivindicación y la de la mayoría de poetas de su tiempo ${ }^{2}$. Los cuatro últimos versos, introducidos por «No sonriáis: ya sé que soy mujer», apelan directamente a esta segunda figura de sí misma.

2 Los siguientes versos del poema «No le pido a los seres perdón por mi existencia», de Julia Uceda, son un claro ejemplo de esta forma de escritura en la que se reclama la libertad de expresión. Así, el sujeto lírico exclama: «No le pido a los seres perdón por mi existencia. / La levanto y la empuño como a un viento domado. / [...] Existir sobre todo. Adoro la presencia / de la luz que la sombra quisiera haber cegado, / el rumor de mi sangre, la dulce incontinencia / del labio que otra carne quisiera sepultado» (Uceda, 2002: 86). 
La toma de conciencia es rotunda y advierte un final dramático, en el que el yo lírico recalca la imposibilidad de la mujer de alcanzar sus deseos por encontrarse subyugada al varón en todas las facetas de su vida, al tener que responder a lo que se espera de ella, al rol que le ha sido impuesto tradicionalmente.

\section{LA SOLEDAD COMO PREMISA DE VIDA}

Son muy interesantes las referencias explícitas a sus influencias poéticas y literarias, las fuentes de las que ha bebido sutilmente, tomando solo lo imprescindible y dejando aquello que la alejaba de su personalidad como escritora. La propia Lagos reconoce a Florencia María Ortiz — que la entrevista en Palma de Mallorca el 3 de julio de 1959- que entre ellas figuran poetas como Juan Ramón Jiménez o Luis Cernuda ${ }^{3}$, este último por lo que significa para la Generación del 27 y por uno de los motivos fundamentales de su obra, la soledad:

-De esa generación, si debiera decidirse por un solo poeta, ¿cuál sería?

—Luis Cernuda.

— ¿Por qué?

- Me da una inmensidad; me abre un gran mundo poético, con el que no hubiera tomado contacto si no le hubiera leído; fue así... o es que fue la confirmación, la claridad, de lo que yo llevaba en mí... lo que yo pretendo y busco en la poesía está en él.

- ¿Tardó mucho en descubrirlo?

-Pues sí; bastante; [...] yo creo que a Cernuda le debo (mi deseo de soledad lo tenía ya) el no temerle a la otra soledad... — ¿Qué soledad?

- La de quedarme a solas con mi obra; y ese miedo él me lo ha hecho perder; prescindir de los demás, del mundo de los poetas, para recluirme cada vez más en esa íntima soledad en compañía de la obra... y le tengo gratitud por lo que me ha hecho ver... me ha enriquecido (en Gómez Gil, 1981: 63).

3 Me refiero sobre todo a La realidad y el deseo de Cernuda y a la obra completa de Juan Ramón, a quien se dedica el primer número de Ágora, tal como recuerda Gómez Gil (1981: 37). 
En el soneto "Otra vez», de La soledad de siempre, el sujeto lírico manifiesta la inseguridad que le produce sentirse lejos de la soledad, recordando, de este modo, los versos de Cernuda: «Cómo llenarte, soledad, / sino contigo misma...» (Cernuda, 1982: 189). A pesar de parecer una paradoja, la realización total del yo poético es equiparable al encuentro aislado de la escritora frente a su obra, sin miedos ni reservas, en esta pugna entre la realidad y el deseo cernudianos:

OTRA vez a soñar desde el oscuro imposible por qué, mano tendida, intentando apresar amor y vida, fijarle a lo inseguro lo seguro.

Otra vez cabalgando hacia tu muro, soledad que me tiras de la brida, seguidora incansable de mi huida, vencedora en la lucha en que perduro.

Otra vez mirar arena y cielo en tu playa sin fin siempre desnuda, bebiéndome el silencio que te nombra.

Otra vez como ayer perdido el vuelo por el salto hacia atrás de miedo y duda, seguida y seguidora de tu sombra (Lagos, 1976: 79).

El motivo, de crucial importancia para ella, no siempre aparece en sus composiciones de forma tan amable y consoladora. En la siguiente estrofa del poema que lleva el mismo título que la obra, la soledad es lo único que sobrevive al fracaso humano, tal y como aparece en el último verso:

Hoy pongo en pie las cosas que sin ser casi fueron y desde su caída esperan este instante.

Hoy pongo en pie fracasos, lo vulgar y lo oscuro, lo cobarde y mezquino, porque a veces, el brillo, es soñarse osadías, o dar saltos audaces en el trapecio-mundo. Pero queda lo otro, lo que nos muerde y calla. La soledad de siempre (ibíd.: 74).

Poemas de Tema fundamental como "Por volverlo a escuchar», «Dimensión imposible»y «Todo es presentimiento» son muestra 
de la influencia de Cernuda, quien en su producción recoge temas como la angustia, la tristeza, la desolación ante la incapacidad del ser humano de alcanzar sus deseos por encontrarse frente a su realidad terrenal. Así, por ejemplo, la imposibilidad de ascensión existencial, la inquietud del sujeto lírico frente a sus anhelos inalcanzables, se aprecia en estos versos del último de los poemas referidos:

CREEMOS ascender alegremente y de pronto, peldaño tras peldaño, el descenso de nuevo.

Duele perder terreno, sentir peso en las alas, y duele este empeñarse otra vez el paisaje (ibíd.: 121).

La temática existencial late en la obra de Cernuda, canalizada en versos como «Tú justificas mi existencia. / Si no te conozco, no he vivido; / si muero sin conocerte, no muero, porque no he vivido» (Cernuda, 1982: 151). El ansia de sublimidad amorosa, que aparece como una cuestión cuasi mística (el eco de los místicos españoles, sobre todo de santa Teresa, es evidente en estos versos), es la base de determinadas composiciones de Lagos, no solo de sus obras más existenciales, sino también de poemas incluidos en otros libros. En "Yo te sueño tan alto», de Luna de enero, de nuevo vemos la influencia del poeta del 27 , ya que el sujeto lírico solo se siente realizado en la medida en que se reconoce a sí mismo amado y aceptado por el otro, al que busca incansablemente. El encuentro recuerda la literatura mística:

OTRA vez primavera por los parques de siempre.

Volvemos a encontrarnos con la fecha de entonces borrándole al olvido aquel punto y aparte.

A buscarme saliste con temor de mi ausencia y yo estaba arropada en el ayer tan nuestro que casi me rozaba tu mano al extenderse.

Ya es hora de ponernos en orden las preguntas. Sabernos en lo justo con Dios en la mirada, tendiéndonos un puente por el pulso y la sangre.

Puedes pedirme el agua para tu sed antigua, ofrecerme el descanso de tu pecho intranquilo y tierra de tu tierra en este breve plazo. 
Yo te sueño tan alto por volarme a tu cima, porque solo en la altura insisto en encontrarte repartiéndonos nubes y el paisaje del viento (Lagos, 1976: 79).

En las distintas entrevistas recogidas por Gómez Gil, Lagos afirma haber leído a otros muchos poetas y haber incorporado algunos de sus rasgos en su propia obra; sin embargo, interesa la siguiente observación de este estudioso: «En Tema fundamental se nos presenta una lectora atenta de san Juan de la Cruz y de santa Teresa» (Gómez Gil, 1981: 167).

Lo anterior queda patente en la mayoría de los poemas de este libro. Aunque no se trata de un símbolo que impregne toda su obra, la luz es el eje central o hilo conductor de este poemario. $\mathrm{Su}$ importancia radica en que se nos presenta como solución a la problemática existencial del sujeto lírico; se relaciona, además, con otros símbolos tales como el cielo, unido al vuelo, a la altura y al color azul, vinculados todos con el ansia de sublimidad del sujeto lírico. El siguiente soneto es una clara muestra del eco sanjuanista:

SALIÓ a buscar estrellas, vano intento.

Altas huyeron por la noche oscura.

Imposible alcanzar tan alta altura, pero el vuelo inicial quedó en el viento.

Nueva cima de luz le infundió aliento; otra vez más por alto su aventura.

Darle alcance soñaba la segura constancia de su vuelo en seguimiento.

Bajo el cuchillo de la noche fría, por los lentos espacios del deshielo, sin descanso siguió y sigue y sigue.

Tras la imposible estela, noche y día, aparejado el vuelo en otro vuelo, quemándose en el rastro que persigue (Lagos, 1976: 111).

Advertimos en el poema la pugna existencial del sujeto lírico, aspirante a alcanzar la verdad última y, a la vez, consciente de la imposibilidad humana de lograrla. La intertextualidad con «Noche 
oscura del alma» es evidente; los términos que usa la poeta son pieza clave para descubrir que ambos textos están en diálogo: vano, vuelo, noche oscura, alta altura, cima de luz, aventura, segura, signió y sigue y sigue, quemándose son algunos de los vocablos o sintagmas que, bien porque aparecen en el poema de san Juan de la Cruz, bien gracias a la paronomasia o a la asociación con determinados campos semánticos relacionados con la literatura mística, nos presentan la influencia de este autor en su obra más existencial.

En relación con la influencia mística en los poemarios existenciales de Lagos, hemos de atender a las consideraciones de $\mathrm{M}^{\mathrm{a}}{ }^{\mathrm{a}}$ Ángeles Hermosilla Álvarez acerca del lenguaje místico y la importancia del silencio en composiciones de autoría femenina. Tras hacer alusión a determinados versos que ponen de manifiesto el mutismo al que se ha visto sometida la mujer en España durante siglos, expone que el discurso propuesto por las teorías feministas presenta y defiende una nueva concepción del silencio, a través de una «escritura que permita resignificar la realidad» (Hermosilla Álvarez, 2015: 14). Así, es significativo atender a lo siguiente:

Aparece en Luce Irigaray, cuando se ocupa del discurso místico, y en Hélène Cixous, al reivindicar una «escritura femenina» en pugna con la lógica falogocéntrica basada en un pensamiento de oposición entre lo masculino y lo femenino, que, no exclusiva de las mujeres, pretende subvertir el orden patriarcal hegemónico y subraya la significación del silencio que se esconde debajo de las palabras.

La escritura entonces se modifica. Buscando mayor expresividad, parece callar para abrir un espacio de sugerencias en el que tenga cabida el lector o lectora (ibíd.: 13).

En La soledad de siempre encontramos evidencias del silencio místico al que remite Hermosilla en su artículo. Así, poemas como «Todo será silencio», «Lo que no tiene nombre», «Tal vez se llame duda» e «Invéntame palabras» son muestra cierta de la necesidad de nuestra poeta de emprender la búsqueda de un lenguaje lírico que le permita expresar sus anhelos existenciales, al que se llega irremisible y finalmente a través del silencio y a favor de los sentimientos y las sensaciones. Además, este es también uno de los motivos fundamentales de las poéticas del medio siglo. Podemos comprobarlo en el siguiente poema: 
SE me cegó de pronto el paisaje más claro y me duelen las manos de tantear tinieblas. ¿Pozo? ¿Abismo? ¿Silencio?

Lo que no tiene nombre.

¿Es la nada, Dios mío, o es tan solo dolor?

El dolor de morirse desde aquí, por la vida (Lagos, 1976: 122).

Como se observa, el sujeto lírico expresa la incapacidad de transmitir el dolor de su propia existencia; además del título, las interrogaciones retóricas y la apelación directa a Dios refuerzan la idea de la imposibilidad de comunicación. En el poema "Con mi paso en tu huella», de Tema fundamental, Lagos confiere mucha fuerza al silencio y a su supremacía:

Puedo decir palabras, me están naciendo altas como un rumor de estrellas.

Puedo decir los sueños,

pero dejo al silencio que los explique exactos (ibíd.: 120).

En el siguiente fragmento de «Invéntame palabras» ocurre lo mismo, aunque, en este caso, Lagos pone en relación el misticismo con la poesía pura, como única vía posible para alcanzar la sublimidad de la existencia a través del lenguaje, por lo que la composición ofrece una clara influencia de las ideas líricas de Juan Ramón Jiménez («intelijencia, dame / el nombre exacto de las cosas!»), otro de los autores más leídos por la autora:

INVÉNTAME palabras que me acompañen siempre, que se me queden limpias, incrustadas en nombres.

Dámelas tan sencillas

como una miel primaria de remota colmena.

Dámelas contenidas, gozosas, apremiantes, que afloren milagrosas como un agua de gruta, como un trigal maduro

a la altura del pecho.

Dámelas con silencio de escondidos caminos (ibíd.: 123).

Otro de los recursos utilizados por Lagos en toda su poesía existencial, herencia de Hijos de la ira (1944) de Dámaso Alonso, es la apelación directa a Dios, a quien en numerosas ocasiones el sujeto lírico desafía. Así, en obras como Para empezar (1962), encontramos una presencia constante de Dios como interlocutor mudo, 
receptor, por una parte, de los lamentos y demandas constantes del yo poético y, por otra, de sus agradecimientos. Aparece también otro tema existencial que preocupa a nuestra autora, la infancia, tal y como se muestra en el poema «Siempre es Tuya la historia»:

Siempre es Tuya la historia.

La del amor y el sueño,

bajo las blancas horas de mano sobre mano

para tejer silencios hasta el porqué del tiempo.

Un «yo» desamparado a veces me arañaba como fantasma niño (Lagos, 1976: 190-191).

Como puede verse, la obra de Lagos está colmada de un sinfin de reminiscencias de la tradición literaria hispánica. Pero tampoco podemos dar por finalizado este apartado sin hacer mención a la influencia que supuso en su producción la obra de sus coetáneos: «el influjo más patente en la obra es el de los últimos poetas del Norte de España: me refiero a José Hierro, Gabriel Celaya, José Luis Hidalgo, Blas de Otero» (Gómez Gil, 1981: 167). «Carta para después», de El corazón cansado (1957), es testimonio fiel de que estas influencias y relaciones no fueron solo literarias:

AMIGOS: Os dejo estas palabras;

volveréis a reuniros y diréis, recordando:

«Parece que fue ayer»; acaso, alguno añada:

«Aquella Concha Lagos...»,

y calle, pensativo y misterioso.

$[\ldots]$

Que no se borre vuestro gesto,

y, por si aún puedo escucharos,

habladme de vosotros,

del café, de poesía,

de las tardes de estío con acacias en flor,

de alguna Antología, del Premio Nacional...

Reuníos nuevamente,

leed vuestros poemas;

un ala de nostalgia rozará vuestras frentes, y acaso alguno diga: "Aquella Concha Lagos...» (Lagos, 1976: 58-59). 
En el poema se da la equiparación entre la autora y el sujeto lírico, que exhorta a sus colegas poetas a que sigan reuniéndose tal como hacían en las tertulias de los viernes de Ágora; quiere que disfruten de la poesía, y que la recuerden como nexo de unión entre ellos y como amante de la naturaleza que rodea su Córdoba natal, «[t]ierra del sur con sus olivos bajos» (ibíd.: 59).

\section{CLAVES POÉTICAS: LOS SÍMBOLOS}

Además de las influencias, para comprender sus composiciones es necesario hacer hincapié en la serie de símbolos que configura su universo poético. Para ello, analizaremos, por una parte, la simbología que Emilio Miró (1976) denomina «viva», y, por otra, la que nosotros, complementando su propuesta, designaremos como «inerte».

\section{SÍMBOLOS INERTES EN LA LÍRICA LAGOSIANA}

El principal de los símbolos «inertes» es la ventana, que actúa como marco con una doble significación: por un lado, Lagos es consciente de que su vida está a la vez sumida y en las afueras de dicho marco. Esta dicotomía hace referencia a la inmersión en la atmósfera de su vida: sus angustias, anhelos y preocupaciones y, por supuesto, su deseo de ser madre. Frente a dicha inmersión, aparece en los márgenes del canon, porque se reconoce escritora y es muy consciente de que ser mujer y escribir con el sello de su propia identidad tiene un precio: el de ser ignorada por sus colegas varones. Así, afirmará en el poema "Ya lo tengo pensado», de El corazón cansado:

Una mujer sabe, desde muy siempre, que no puede volar; y por eso, sin duda, a cada instante piensa las cosas más opuestas.

Una mujer se siente a veces sola. Una mujer descubre cada noche que la ventana es marco de su vida (Lagos, 1976: 57). 
En «El diálogo», de Luna de enero, la autora trata temas como la existencia, el paso del tiempo, el amor y la muerte. Sin embargo, el más destacado es la reivindicación de igualdad: «Alcemos la cabeza / a la igualdad del cielo» (ibíd.: 102). Aparece de nuevo la ventana: «y sombras de mi cuerpo en las ventanas / contemplando paisajes con mis aquellos ojos» (ibíd.: 101); en este caso, el plural nos hace pensar en el paso del tiempo, reforzado con el demostrativo "aquellos», lo que sugiere que han sido varios los «marcos» en los que se ha visto atrapado el sujeto lírico femenino en su juventud.

A este respecto, Esther Tusquets hace una afirmación vigente aún en nuestros días:

Como en muchas otras profesiones, las mujeres han invadido el campo, ocupan un enorme lugar en los espacios medios, pero no alcanzan, en un mundo regido por hombres, los puestos más altos. Para comprobarlo, basta echar una ojeada a la lista de los premios Nobel o al número de mujeres que figuran en la Academia Francesa o en nuestra Real Academia de la Lengua [sic]. A nivel «oficial» apenas existimos (Tusquets, 2007: 13).

Podemos remitir a numerosos datos biográficos que corroboran la reivindicación de identidad implícita en los poemas de Lagos a través del símbolo de la ventana. Estos tienen que ver con su incansable labor en la publicación periódica de Ágora y las relaciones que, gracias a ella, a las tertulias de los viernes en su casa de la actual Gran Vía y al estudio fotográfico de su marido, estableció con muchos artistas (no solo poetas) de la época. En un artículo recogido en un libro que hace justicia a la labor lírica de nuestra autora, Noni Benegas afirma que, en cierta conversación con Uceda, esta reconoció que era la propia Lagos quien, en numerosas ocasiones, tomaba las fotografias a los clientes que visitaban a su marido en el estudio:

Me pareció un hallazgo: Lagos había cogido la cámara infinidad de veces y había congelado a la figura dentro de un marco, de un encuadre.

Ahora ella alzaba una instantánea de sí misma y se veía paralizada, a su vez, dentro de un marco, en la ocasión, el de la ventana. [...] ¿podría escapar la autora de ese marco dentro del marco, es decir, de ese límite normativo que la 
incrustaba en un paisaje previsto de antemano, recortado por el enfoque ajeno, el social de la época? (Benegas, 2011: 141).

Indudablemente, deberíamos responder a esta interrogación de Benegas con una aseveración: por supuesto que sí, a través de su poesía. Sin embargo, también nos quedan pruebas de que esta labor no fue fácil y para obtener datos a este respecto es necesario acudir a una de sus prosas inéditas, una parte de sus memorias recogidas en $\mathrm{La}$ madeja ${ }^{4}$. De las páginas de esta obra de carácter autobiográfico extraemos información de incalculable valor, que incluye datos muy relevantes: el primero, que presentó Tema fundamental al Premio Nacional de Poesía y el jurado falló a su favor, pese a lo cual dicho merecimiento le fue arrebatado y concedido a García Nieto, con quien terminó su amistad tras este hecho; el otro tiene que ver con su crítica explícita a las antologías poéticas del momento, de las que reconoce: «Lo triste es que algunas se hacen hoy solo para satisfacer venganzas personales, otras se reducen a un intercambio divertido: tú me incluyes a mí, yo te incluyo a ti...» (Lagos, 1978: 14). A pesar de esta feroz crítica al mundo literario de su época, conformado sobre todo por varones, lo cierto es que sus relaciones, profesionales y personales, estuvieron rodeadas de ellos: en las páginas de este libro, aparecen infinidad de nombres de poetas del momento; además, reconoció que su padre y su marido fueron dos pilares fundamentales en su quehacer poético, algo que no alcanzó a ser para ella su madre, debido a la influencia que los postulados de la sociedad patriarcal habían ejercido en su vida.

\section{SÍMBOLOS VIVOS EN LA POESÍA DE CONCHA LAGOS}

Con referencia a los símbolos «vivos», Emilio Miró considera que

[e]l contacto afirmativo, esperanzado, de su poesía, surge de los espacios abiertos, de su instalación y su contacto en y con la realidad natural, la Naturaleza viva y vivificadora. Agua, tierra,

4 Obra inédita de Concha Lagos que se encuentra custodiada por la Unidad de Estudios Biográficos de la Universidad Autónoma de Barcelona, a la que he tenido acceso gracias al profesor Blas Sánchez Dueñas. 
cielo, podrían formar un triángulo básico, indestructible, en la poesía de Concha Lagos (Miró, 1976:11-12).

Como expone Miró, toda su poética se centra en estos tres símbolos. En cuanto al agua, está íntimamente relacionada con la infancia, la vitalidad, la pureza de lo primitivo; recordemos que para ello no ha de estar estancada, como ocurría en la obra de Lorca, en la que el pozo representaba la podredumbre y la ausencia de vida ${ }^{5}$. La relación de la pureza del agua con la infancia no es arbitraria, puesto que para nuestra autora la vuelta al primitivismo y la inocencia forma parte de lo que Estel Juliá define como "[1]a Infancia como estado ideal» (Julià, 2010-2011). En relación con este símbolo encontramos dos obras fundamentales, Agua de Dios y Arroyo claro, ambas de 1958. Como subraya Isabel Paraíso, estos poemarios son «dos libros gemelos, deliciosos, centrados en la infancia externa» (Paraíso, 2011: 73). En el poema «Los niños de que hablo», de Agua de Dios, la poeta escribe:

Todos los niños de que hablo guardan las menuditas piedras del camino y llevan un tesoro en los bolsillos. Los niños de que hablo, a veces, dicen palabras que me asustan, como «mañana», "cuando sea mayor»... Los niños se me inquietan por las venas, y desato preguntas cara al cielo.

Dios, desde su baranda, los contempla (Lagos, 1976: 89).

Como se observa en los versos anteriores, Lagos ve en la infancia aquellos ideales originarios con los que, inexorablemente, rompemos al llegar a la madurez: los niños son el ejemplo más depurado de la sencillez, de forma que la llevan a desatar «preguntas cara al cielo». Esta forma de increpar a Dios guarda relación directa con la existencia, a la que hace referencia a través de los pequeños al

5 Recordemos, por ejemplo, "Niña ahogada en el pozo», de Poeta en Nueva York (1940), que comienza con esta estrofa: «Las estatuas sufren con los ojos por la oscuridad de los ataúdes, / pero sufren mucho más por el agua que no desemboca. / ...que no desemboca» (García Lorca, 2008: 178). Los versos muestran la ansiedad que provoca al sujeto lírico el agua estancada en el pozo, algo completamente contrario a la simbología del agua presente en la obra de Lagos. 
recoger lo que dicen. La poeta reconoce que son «palabras que me asustan». Lagos desea volver al primitivismo de esta etapa de la vida:

Estos niños del libro que nos ocupa, fuera de sus divergencias o actitud, parecen llevados un tanto conminativamente de la mano por nuestra poeta conjeturándose un rebote de sí misma, en su retrogresión a su propia infancia de ideas e ideales, con un cierto narcisismo o coquetería que va de lo infantil hasta el deje maternalista (Gómez Gil, 1981: 89).

El segundo símbolo es la tierra, que está muy ligada a la soledad, a la angustia frente a los desastres humanos, a la presencia constante de la muerte, además de traer consigo de nuevo reminiscencias de la infancia. El tema del otro está muy presente en obras como La soledad de siempre, Los anales (1966), Diario de un hombre (1970), El cerco (1971), La aventura (1973) y Fragmentos en espiral desde el pozo (1974). En "Los pasos por el tiempo", de La soledad de siempre, se aprecia la relación entre el símbolo y la otredad; la tierra es el lugar donde tenemos contacto con el otro y en el que naturaleza y humanidad se funden:

En todos los espejos he buscado otros rostros, porque ignorar no quiero ni la rama ni el árbol. $[\ldots]$

Por eso quiero hablaros de cosas que he mirado, decir desde mi tarde lo que la vida ofrece: puedo hablar de la tierra que dilata los ojos, $[\ldots]$

Pero un silencio late medroso por mi pulso; y mi afán de deciros, de adentrarme en vosotros, quedará en el misterio, en niebla de esa niebla que diluye las cosas y nos borra del tiempo (Lagos, 1976: 74-75).

El sujeto lírico, ya en la etapa de la madurez («decir desde mi tarde»), reflexiona sobre la existencia, anunciando que el final ineludible de todo ser humano es la muerte. Asistimos al diálogo del yo lírico con su "otro yo», que es en realidad un enfrentamiento existencial que lo lleva a ansiar que su palabra sea eterna, algo que se contrapone a su realidad efimera y terrenal. 
En el poema "Homo sapiens», de La aventura, destacan unos versos en los que la autora resalta la crueldad de la realidad humana, reconociendo el pesar de nuestra propia existencia en el otro:

Aún somos más lo otro: el «animal de fondo».

Solo huesos con nombre:

$[\ldots]$

El hombre, siempre el hombre

provocando las guerras y vendiendo metralla

a cambio de la sangre.

El hombre,

El que inventa crueldades y acumula monedas,

El hombre.

Judas multiplicado sin remisión posible (ibíd.: 307-308).

La perspectiva con la que Lagos aborda la existencia del ser humano y la problemática del hombre como animal racional es desesperanzadora: la maldad humana parece irremediable, aunque encuentra salida en la vuelta a la inocencia de la infancia y se ve mermada con el descubrimiento del amor, que hace al "yo» más humano al reconocerse amado por el otro.

Pese a ello, en determinados poemas, Lagos ofrece una perspectiva más positiva y alentadora, en la línea de estos versos de Ángel González: «Perdida la de ayer, la de hoy perdida, / no me doy por vencido, y sigo, y juego // lo que me queda: un resto de esperanza» (González, 2011: 128). Así, en El corazón cansado, escribe Lagos: «Nunca estamos vencidos. / Hay siempre una esperanza mojándonos la frente» (Lagos, 1976: 52).

El último de los símbolos es el cielo, que es susceptible de ser identificado con las cuestiones puramente existenciales, la búsqueda de identidad, por un lado, como mujer, por medio de la maternidad, y, por otro, como escritora, a través de la palabra. Aparece de forma explícita la desilusión ante el deseo malogrado de ser madre en poemarios como Los obstáculos, El corazón cansado, La soledad de siempre, Tema fundamental o Golpeando el silencio. En un poema de Los obstáculos, se aprecia el desdoblamiento del yo poético y asistimos al reconocimiento de su propia existencia:

MIRADME bien.

Yo no soy esa que conocéis,

que conocemos. 
Que habla, discute, va, viene:

se queja, dice «sí», «no",

$\mathrm{y}$ a veces enloquece por cosas pasajeras.

No, no he sido nunca esa y, sin embargo,

he peinado con gracia sus cabellos.

He vestido su cuerpo, he sonreído,

he dicho "esto me gusta»;

y he sufrido por penas tan de ella...

Hoy mismo,

¡qué sorpresa al mirarme las manos!

Sus manos, su cintura,

Y esos ojos donde luchan a un tiempo la burla y la tristeza.

Qué extraño y complicado...

$\mathrm{O}$ acaso tan sencillo que no puede explicarse

(ibíd.: 41).

Estos versos son una clara muestra de que el sujeto lírico femenino reconoce y manifiesta su identidad, algo que se advierte en el lenguaje que utiliza: por un lado, el uso de la primera persona del singular remite a la identificación «mujer-poeta» unidas en un mismo ser; por otro, los términos escogidos transmiten la necesidad de encontrar una nueva forma de expresión que le permita hablar en libertad y ser ella misma ( No he sido nunca esa y, sin embargo, / he peinado con gracia sus cabellos. / [...] Hoy mismo, / iqué sorpresa al mirarme las manos!»).

\section{LA MATERNIDAD: DESEO, FRUSTRACIÓN Y DOLOR EXISTENCIAL}

La maternidad en la obra de Lagos presenta matices y perspectivas diversas, aunque tenga como connotación central lo trágico. Desde corrientes como la de E. Showalter, el tratamiento de este asunto tendría que ver con lo que la autora denomina literatura «femenina», en la que advierte

una cuestión de punto de vista a la hora de ver la vida, de escribir, de plantear la relación con el mundo o de 
interpretarse en él y de relacionarse y vincularse con los demás o con la escritura. Esta directriz vendría determinada por unos temas, unos gustos o unas actitudes propios de la femineidad como podrían ser la maternidad, [...] los sentimientos, las pasiones, las experiencias personales y sensaciones sexuales de un cuerpo femenino, etc. (en Sánchez Dueñas, 2009: 112).

El poema "Ya lo tengo pensado", de El corazón cansado, es una muestra de este tipo de escritura en la que no hay atisbo de rebeldía, sino aceptación del destino y toma de conciencia del sujeto lírico femenino acerca de su propia existencia. El sentido de su vida se encuentra en la ansiada maternidad, que se presenta incluso como forma de conocimiento:

Ya lo tengo pensado:

dejaré de soñar.

Iré sencillamente por la vida,

sin inventar nuevas historias.

Me sentaré a la mesa

y partiré mi pan.

Una mujer puede quedarse

de espaldas a las cosas,

si tiene en su regazo un ser pequeño,

y hasta cerrar los ojos

y decir que comprende lo que no ha visto nunca

(Lagos, 1976: 56).

Atendiendo a la afirmación de la autora, entendemos hasta qué punto su infecundidad influyó en su visión del mundo y de su propia existencia: «He fracasado en todo lo que más deseaba: hijos, carrera, viajes y, sobre todo, volver a tener un jardín como en la infancia. Algo se ha interpuesto siempre» (en Gahete Jurado, 2011: 124). Por esta razón, temas como la infancia y los niños son para Lagos punto clave en su poesía y, de acuerdo con Stefan Bollmann,

[t]radicionalmente, la mujer ha estado más cerca del mundo de la infancia que el hombre [...] La imagen de la mujer era la de una intermediaria entre el mundo de los pequeños y el de los grandes, entre deseo y razón, entre imaginación y sentido de la realidad (Bollmann, 2007: 71). 
Agua de Dios y Arroyo claro son dos poemarios dedicados a la infancia y a los niños en los que, en ocasiones, se advierte el dolor, no ya de un sujeto lírico femenino que siente coartada su existencia debido a la esterilidad, sino de la propia Concha Lagos, a quien Dios no ha dado el don de ser madre.

En el poema «Dejádmelos nombrar», perteneciente a Arroyo claro, Lagos refleja la maternidad desde la angustia existencial, y en otras composiciones lo tratará de forma aún más obsesiva y desesperanzadora:

DEJÁDMELOS nombrar.

He tenido sus nombres anidándome hondo.

Se llamaron primero con nombres fantasía,

luego tuvieron otros, más de verdad y de siempre,

como Manuel o Juan.

Corrieron de mi mano por un mundo

que yo inventé despacio.

$[\ldots]$

Me han quedado sus nombres porque esto no se olvida, aún los pronuncio en sueños y puede que despierta (Lagos, 1976: 93).

En estos versos, la autora muestra su ansiado deseo de ser madre; de ahí que escriba los nombres de niños que son solo ensoñación, que no pertenecen al plano real. En esta misma línea, el poema "Juegos», de Agua de Dios, pone de manifiesto de nuevo su deseo. La composición está integrada por tres estrofas: las dos primeras, de cuatro versos, y la última, de un solo verso. El sujeto lírico femenino, después de revelar cómo juegan los pequeños y de un silencio marcado por el cambio de línea en la escritura, afirma: "Yo miro mi regazo ausente de la fiesta» (ibíd.: 91).

El corazón cansado recoge "Carta a lo azul», donde el sujeto lírico, identificado con la propia poeta, alza un grito al cielo, pidiéndole a Dios que le conceda el milagro de ser madre:

Tú me harás el milagro.

Hoy mi sed te lo pide, te lo pide mi campo sin fruto, sin alondra, lo frágil de este barro, la luz que se me apaga y la cruz de mis brazos. 
Por la breve esperanza, por aquel largo llanto, por aquella agonía, porque me fue vedado conocer las señales y el eco de otros pasos al compás de los míos, Tú me harás el milagro.

Yo no tuve semilla, yo no tuve en las manos esa flor diminuta que llueve de tu mano.

Yo no tuve canciones. Cuando hiciste el reparto. de pájaros y estrellas, olvidaste mi árbol.

¡Señor!, desde tu cielo, estréname un milagro (ibíd.: 57-58).

El clamor del sujeto lírico femenino por la desolación ante su deseo frustrado de ser madre es evidente. Sobre el asunto, María Payeras Grau, en un artículo dedicado a la obra poética de Pilar Paz Pasamar, expone:

En una sociedad donde la fertilidad de la mujer mide su valor social, la falta de descendencia se convierte en una tragedia que rebasa la dimensión íntima, pues la convierte en una mujer sin voz, una mujer que no se proyecta socialmente más allá de sí misma porque carece de lo que le da valor a los ojos de la comunidad (Payeras, 2013: 24).

La tragedia de la que habla Payeras llevaría a Lagos a escribir como única salida frente a sus angustias y desvelos, y a que sus obras fueran su legado y el de su esposo, Mario Lagos; de ahí que el pseudónimo escogido para su labor literaria llevara este apellido. Por tanto, las obras de nuestra poeta son los hijos cedidos a la historia de la literatura española, con los que logra superar la frustración de la esterilidad. 


\section{BIBLIOGRAFÍA}

Balcells, José M. ${ }^{a}$ (ed.) (2003). Ilimitada voz. Antología de poetas españolas 1940-2002, Cádiz, Universidad de Cádiz.

Benegas, Noni (2011). "Concha Lagos y la poesía femenina de su tiempo", en Concha Lagos y el panorama literario de su tiempo, eds. Blas Sánchez Dueñas y M. José Porro Herrera, Córdoba, Diputación Provincial de Córdoba - Universidad de Córdoba, pp. 135-149.

Bollmann, Stefan (2007). Las mujeres que escriben también son peligrosas, Madrid, Maeva Ediciones.

Cernuda, Luis (1982). La realidad y el deseo, ed. Miguel J. Flys, Madrid, Castalia.

Gahete Jurado, Manuel (2011). «Concha Lagos: poética de la pasión», en Concha Lagos en el panorama literario de su tiempo, eds. Blas Sánchez Dueñas y M. José Porro Herrera, Córdoba, Diputación Provincial de Córdoba - Universidad de Córdoba, pp. 115-133.

García Lorca, Federico (2008). Poeta en Nueva York, ed.

María Clementa Millán, Madrid, Cátedra.

García Tejera, Carmen y Fernández Guerrero, José Antonio (2003). Poetas andaluces de los años cincuenta. Estudio y antología, Sevilla, Fundación José Manuel Lara, pp. 447-477.

- (2005). «Perfil literario de la poesía andaluza de los cincuenta», Ateneo. Revista Cultural del Ateneo de Cádiz, 5, pp. 207-210.

Gómez Gil, Alfredo (1981). Concha Lagos bajo el dominio de la literatura comparada, Alicante, Publicaciones del Instituto de Estudios Alicantinos.

GonzÁlez,Ángel (2011). Palabra sobre palabra. Obra completa (19562001), Barcelona, Seix Barral, 1. ${ }^{a}$ ed. aum., 10. ${ }^{a}$ reimpr.

Hermosilla Álvarez, M. ángeles (2015). «Silencio y poesía: el misticismo en la lírica española de autoría femenina», Ámbitos. Revista de Estudios de Ciencias Sociales y Humanidades, 33, pp. 13-22.

Julià, Estel (2010-2011). «Los siete itinerarios del exilio interior de Concepción Gutiérrez Torrero (Concha Lagos)», Espéculo: Revista de Estudios Literarios, 46. https://pendientedemigracion.ucm.es/info/especulo/numero46/colagos.html Lagos, Concha (1976). Antología 1954-1976, ed. y prólogo de Emilio Miró, Barcelona, Plaza y Janés.

- (1978). La madeja, inédito. 
Mıró, Emilio (1976). «Prólogo» a Concha Lagos, Antología 1954-1976, Barcelona, Plaza y Janés.

Paraíso, Isabel (2011). "Concha Lagos, infancia y canción», en Concha Lagos en el panorama literario de su tiempo, eds. Blas Sánchez Dueñas y M. José Porro Herrera, Córdoba, Diputación Provincial de Córdoba - Universidad de Córdoba, pp. 69-86.

Payeras Grau, María (2013). «Pilar Paz Pasamar en su creación

poética inicial. Persiguiendo verdades», Ámbitos. Revista de Estudios

de Ciencias Sociales y Humanidades, 29, pp. 21-31.

Rosal, María (2010). «Las poetas de fin de siglo», Anuario de Estudios Filológicos, xxxIII, pp. 239-251.

Sánchez Dueñas, Blas (2009). Literatura y feminismo. Una revisión de las teorías literarias feministas en el ocaso del siglo xx, Sevilla, ArCiBel Editores.

- (2011). «Concha Lagos: actualidad y novedad desde la revisión crítica», en Concha Lagos en el panorama literario de su tiempo, eds. Blas Sánchez Dueñas y M. ${ }^{a}$ José Porro Herrera, Córdoba, Diputación Provincial de Córdoba - Universidad de Córdoba, pp. 7-51.

Tusquets, Esther (2007). «Prólogo» a Stefan Bollmann, Las mujeres que escriben también son peligrosas, Madrid, Maeva Ediciones, pp. 8-15.

Uceda, Julia (2002). En el viento, hacia el mar (1959-2002), ed. Sara Pujol Russell, Sevilla, Fundación José Manuel Lara. 